\title{
Hikers' Motives for Choosing a Hiking Trail - Evidence from the Czech Landscape Protected Areas
}

\author{
Michaela Antoušková $^{1}$, Jana Mikulec $^{2}$, Alena Kolářová ${ }^{3}$ \\ ${ }^{1,3}$ Department of Economics, Faculty of Economics and Management, Czech University of Life \\ Sciences in Prague, 16521 Prague, the Czech Republic \\ ${ }^{2}$ Faculty of Environment, Czech University of Life Sciences in Prague, 16521 Prague, the Czech \\ Republic
}

\begin{abstract}
The article aims to extent the previous studies dealing with hiking and hikers' characteristics by focusing on hikers' motives for coming to nature based recreation areas and their motives for choosing a hiking trail. The special attention is paid on tourists coming for sportive motives. To estimate the odds by which the hikers choose a hiking trail, logistic regression is applied, and seven logit models are developed. The dependent variables in estimated models are, besides the motives for choosing hiking trail, also gender, age and education. Data for estimated model were gathered through respondents' surveys in protected landscape areas in the Czech Republic. Results show that hikers choose a trail mainly according to the surrounding landscape appearance. The research also proved that sportive reasons are more likely to choose a hiking trail according to the length of the trail and the position of start/finish than hikers coming for nature. The hikers profile fits the hikers' profiles found in other empirical studies.
\end{abstract}

\section{Introduction}

The research about hikers' experience and characteristics has been conducted by several authors [1-5]. Lynn and Brown [5] who studied effect of recreational use impacts on hiking experience in natural areas (Starkey Hill, Canada) determined the typical hiker in the age category of $18-83$ years with a mean age of 38 years. In their research, $85 \%$ of hikers had completed their college or university degree. Torbidoni [4] who studied the recreational experience in Mont-Rebei reserve, Port d'Arnes Reserve and Can Macana Reserve (Spain) found out the typical hiker is a male with an average age of 45 years. Most of the respondents had finished their university degree. Wall-Reinius and Back studied changes in hikers' demand in Sweden and compared studies from the year 2003 and 1980. They found out that hikers' characteristics reflect to the basic general demographic characteristics. The population ageing reflects to the lower percentage of hikers under the age of 40 years (in 1980 it was 65\% hikers; in 2003 it was $38 \%$ hikers) [6].

A little research has been conducted also in the Czech Republic. Nykodym and Mitas's research [7] studied the physical activities in the South Moravian region and found out that hiking is the second most popular physical activity for women, just behind cycling. For men, hiking is the third most popular physical activity, behind cycling and football. However their research was not focused on hikers in detail. Therefore this paper intents profound the knowledge about hikers' characteristics and focuses on their motive for choosing hiking trail. 
The overall aim of the research is specified as identifying hikers' profile and determination key factor influencing the decision made about choosing the hiking trail. The particular focus will be paid on hikers with sportive motives (SM) and following question will be answered:

- Is there a statistical significance in hiker's profile between hikers coming to studied nature based areas for sportive motives and those coming for other motives? (hypothesis to be tested: $\mathrm{H} 0$ - there is no difference in personal characteristics between hikers coming for sportive motives and those coming for other motives).

- What are the odds that hikers coming for sport motives to studied areas choose a hiking trail according to preferred motives in comparison to those coming for other motives?

\section{Methods}

The research was conducted in recreational nature areas ensuring variety in hiking conditions and motives for choosing a hiking trail: landscape protected areas (LPA) - Kokořínsko, Železné Hory, Český Kras and Blaník (see table 1)

Table 1. Studied Areas

\begin{tabular}{|c|c|c|}
\hline Name of LPA & area & specifics \\
\hline Kokořínsko & $272.66 \mathrm{~km}^{2}$ & $\begin{array}{c}\text { 143 sections of hiking trails; characterized by various objects formed } \\
\text { by selective erosion and the variety in vegetation species. The tourist } \\
\text { activity is supported by original architecture and historical objects. }\end{array}$ \\
\hline Železné Hory & $285.87 \mathrm{~km}^{2}$ & $\begin{array}{c}160 \text { sections of hiking trails; characterized by high forest coverage. } \\
\text { Despite long populating it preserves many nature places. }\end{array}$ \\
\hline Český Kras & $132.25 \mathrm{~km}^{2}$ & $\begin{array}{c}62 \text { sections of hiking trails; formed along the Berounka River. This } \\
\text { area represents the largest karst location in the Czech Republic with } \\
\text { valuable thermophilic oak and hornbeam forest. }\end{array}$ \\
\hline Blaník & $40.31 \mathrm{~km}^{2}$ & 11 sections of hiking trails, valuable acidophilic beechwood forests \\
\hline
\end{tabular}

\subsection{Data Collection}

Hikers' surveys were conducted from April to September 2011. Data were collected on the 80 crossing trail spots to ensure the reliably of data. Hikers were questioned in face-to-face interviews to ensure that respondents understood properly asked questions.

The questionnaire was divided into two main parts. The first part studied the hikers' motive to come to studied areas and preferences to choose a hiking trail: sport, being in nature, seeing cultural/natural attractions, visiting friends and relatives, business purposes, and stop over on their further journey. Consequently, hikers were questioned about their motives for choosing a hiking trail: length of trail, landscape appearance, trail leads along the settlements (folk architecture), trail lead through forest, natural and cultural sightseeing, location of starting point and finish of the trail, good transport accessibility, other reason not specified above. The second part focused on hikers' personal characteristics, namely: gender, age and education.

A total of 1443 questionnaires were collected. Conducted Chi-square test (p-value 0,198) shows that the representation of hikers interviewed in the research and the real representation of hikers according to the demographic characteristics is not different; the results are considered as valuable.

\subsection{Logit Model Set Up}

The answers hikers provided are transformed into "yes" and "no" answers, so the binary logit model is developed. The dependent variable in an estimated model is the motive for choosing a hiking trail. The independent variables in studied model match factors that may influence hikers' decision: gender, 
age, the highest obtained education, and reasons for visiting landscape protected areas. Hikers' responses about their preferred motive for choosing a hiking trail enabled to set up seven binary logit models. General model function is determined as:

$\ln (p /(1-p))=\alpha+\beta 1$ (motives for choosing the PLAs) $+\beta 2$ (gender) $+\beta 3$ (age) $+\beta 4$ (education) $+\mathrm{e}$, where, $\ln (p /(1-p))$ is logit or log odds ratio of dependent variable, $\alpha$ is constant, $\beta$ is coefficient of dependent variable, e is error term.

The independent categorical variables in designed models are subsequently coded according to the studied variables. Reasons to visits LPA are coded as: Reasons to visit LPA (1) - being in nature; (2) - natural/cultural sightseeing; (3) - visiting friends/relatives; (4) - business trips; (5) - stop over on further journey; (6) - other motives not specified above. The reference category for Reasons to visit is represented by hikers coming for sport motives.

Category of Gender is coded as: Gender (1) - man; the reference category for Gender is woman. Education is coded as: Education (1) - without an education; (2) - elementary; (3) - high school; (4) college/technical institute. The reference category for Education is hikers with a university degree.

All analysed models are tested by Chi - square test, -2 log likelihood ration as a measure of how well the estimated model fits the likelihood. Tests that explain the variability of the dependent variable are applied - Cox\&Snell R Square and Nagelkerke R Square [8]. Cox\&Snell R Square, Nagelkerke R Square and $-2 \log$ likelihood are for guidance only since they can take moderate or low levels, even when the estimated model could be appropriate and useful, due to the fact that the dependent variable is categorical [9]. Finally the Hosmer and Lemeshow test was applied [9].

\section{Results}

The main motivation for hikers coming to LPAs is being in nature (46.0\%). For natural and cultural sightseeing is $26.3 \%$ of hikers, for sporting activities $10.4 \%$ of hikers, to visit friends and relatives is $6.7 \%$ of hikers. The lowest number of hikers come for business purposes $(3.5 \%)$ and $6.5 \%$ of hikers stop in LPA on their way to other destinations.

Most hikers choose the hiking trail according to landscape appearance (57\%). Concrete objects close to the chosen trail or along the trail are important for $51.7 \%$ of hikers. For a significant part of hikers $(32.8 \%)$ it is important that the trail leads through the forest. The length of trail signifies important reasons for choosing the hiking trail for $13.4 \%$ of hikers. The accessibility of the trail is significant for $11.8 \%$ of hikers and the location of starting point and finish of the trail influences the decision of $10.4 \%$ of hikers. Settlement and surrounding architecture is the least important motive for choosing a hiking trail.

Respondents asked in the survey are women (53.8\%) and men (46.2\%) with an average age of 35 years. The most of the respondents have a university degree $(41.6 \%)$ and high school education (40.6\%), 6.7\% of hikers reach only elementary education, $9.2 \%$ of hikers reach technical institute degree. Without any education there are $1.8 \%$ of hikers. Men tend to choose hiking trails according to the landscape appearance, architecture, settlements, and concrete objects along the trail. The increase in age results in higher odd of choosing the trail according to the architecture and settlement located along the trail. Other age variables are close to one, so no significant relation can be derived. Hikers without education tend to choose a trail according to the landscape surrounding, concrete objects and positions of start and finish than those with a university degree. Hikers with university degrees are more likely to choose a hiking trail according concrete objects, accessibility and position of start and finish than those with elementary education. Hikers with high school education are more likely to choose a hiking trail according to position of start and finish than hikers coming for sportive motives. Hikers coming for sportive motives are more likely to choose according to surrounding landscape, concrete objects and location of start and finish than those with college or technical institute education. 


\subsection{Profile of Hiker Coming Mainly for Sportive Purposes}

Hikers coming to LPAs for sporting purposes choose a hiking trail mainly according to the landscape appearance along the trail $(52.9 \%)$, forest surrounding $(17.6 \%)$, concrete objects along the trail $(10.2 \%)$, position of start and finish (7.3\%), trail length (5.8\%), accessibility (4.4\%), and settlements and architecture along the trail $(1.4 \%)$. There is double the amount of men than females for sporting purposes. The majority of hikers are high school and university educated $(62.3 \%)$. Hikers with elementary education make $26.2 \%$ and hikers with college or technical institute make $10.5 \%$. There are $1 \%$ of hikers without education. The average age of hiker coming for sportive motives to studied areas is 32.8 years.

Based on the results from conducted t-test statistics, which proved not statistical significant parameters, the hypothesis that there is no difference in age between hikers coming for sportive motives and those coming for other motives, cannot be rejected. Similarly, the hypotheses cannot be rejected for parameters of education and gender.

\subsection{Motive for Choosing a Hiking Trail}

\subsubsection{Model 1: Length of Trail}

Logit (length of trail) $=-0.871-0.373$ Motives to visit $(1)-0.784$ Motives to visit $(2)+0.042$ Motives to visit (3) -0.715 Motives to visit (4) -0.198 Motives to visit (5) -0.151 Motives to visit (6) -0.193 Gender (1) - 0.008 Age - 0.443 Education (1) + 0.572 Education (2) - 0.348 Education (3) -0.515 Education (4)

Model 1 reveals that hikers coming to studied areas for SM are 3.12 times more likely to choose a hiking trail according to its length than hikers coming for being in nature. Similarly the odds that hikers choose the trail according to its length is 1.83 times higher by hikers coming for SM than those coming for natural and cultural attractions and 1.95 times higher than for those coming for business purposes. The similar relation between studied dependent and independent variables is seen in other motives for visiting LPAs. The only exception are hikers coming for visiting friends and relatives, those hikers are more likely to choose hiking trails according to the length of trails than hikers coming for sportive purposes.

\subsubsection{Model 2: Appearance of Surrounding Landscape}

Logit (Appearance of surrounding landscape ) $=0.003-0.142$ Motives to visit $(1)-0.812$ Motives to visit (2) - 1.654 Motives to visit (3) - 1.418 Motives to visit (4) -0.085 Motives to visit (5) -0.505 Motives to visit (6) + 0.993 Gender (1) + 0.011 Age +1.342 Education (1) + 0.161 Education (2) 0.030 Education (3) -0.191 Education (4)

Designed model reveals that hikers coming for sportive purposes are 2.25 times more likely to choose hiking trail according to surrounding landscape than those coming to see cultural and natural attractions. Similarly the odd of choosing the trail according to its landscape surrounding is 2.23 times higher by hikers coming for sports than those coming to visit friends and relatives, and 4.13 times higher than by hikers coming for business purposes. There is also statistical proof that men are 1.5 times more likely to choose a hiking trail according its landscape appearance than women.

\subsubsection{Model 3: Architecture and Settlement Along the Trail}

Logit (Architecture and settlement along the trail) $=-4.364+0.704$ Motives to visit $(1)+0.288$ Motives to visit (2) +0.164 Motives to visit (3) +0.198 Motives to visit (4) +0.493 Motives to visit (5) -18.504 Motives to visit (6) + 0.201 Gender (1) + 0.035 Age -17.738 Education (1) +0.435 Education (2) - 0.294 Education (3) - 0.535 Education (4) 
Hikers coming to LPAs for visiting relatives and friends are 1.18 times more likely to choose a hiking trail according the proximity of architecture than hikers coming for SM. Similarly hikers coming for natural and cultural attractions are 1.33 more likely to choose a hiking trail according to the proximity of architecture than hikers coming for SM. Other predictors of motives for coming to studied areas not statistically significant in designed model. Parameter of age is statistically significant on $\alpha=0.05$ level and positive. However $\exp (\beta)$ coefficient is close to zero (1.035), so the relation between age and odd of choosing the trail according to the architecture and settlement along the trail is not clearly defined.

\subsubsection{Model 4: Forest Surrounding Along the Trail}

Logit (Forest surrounding along the trail) $=-0.006-0.083$ Motives to visit $(1)-1.306$ Motives to visit (2) -0.905 Motives to visit (3) - 1.138 Motives to visit (4) -0.946 Motives to visit (5) -0.887 Motives to visit (6) +0.247 Gender (1) -0.005 Age -0.495 Education (1) + 0.623 Education (2) 0.126 Education (3) -0.768 Education (4)

Hikers coming to the studied areas to see cultural and natural attractions $(\exp (\beta)=0.271)$ and hikers coming for visiting friends and relatives $(\exp (\beta)=0.404)$ are less likely to choose the trail according to the fact that the trail leads through the forest than hikers coming for sport. On the other hand, hikers stopping on their way to other destination(s) are 1.64 times more likely to choose hiking trails according to its forest surrounding than those coming for sportive motives.

\subsubsection{Model 5: Concrete Objects Along the Trail}

Logit $($ Concrete objects along the trail $)=0.919-0.910$ Motives to visit $(1)+0.165$ Motives to visit (2) -0.487 Motives to visit (3) -0.813 Motives to visit (4) -0.615 Motives to visit (5) -0.916 Motives to visit (6) -0.270 Gender (1) - 0.001 Age +0.372 Education (1) - 1.376 Education (2) 0.023 Education (3) + 0.187 Education (4)

Analysed model reveals that hikers coming to studied LPAs for other than sportive motives are more likely to choose a hiking trail according concrete objects along the trail than those coming for sportive motives. The statistically proved predictors are hikers coming for cultural and natural attractions $(\exp (\beta)=15.387)$; hikers coming for visiting friends and relatives $(\exp (\beta)=34.226)$; hikers stopping on their further journey $(\exp (\beta)=1.626)$. Statistically significant parameter on $\alpha=0.05$ level is a predictor of education. Not educated hikers are 20.724 times more like to choose the hiking trail according to the concrete objects along the trail than those with university degree.

\subsubsection{Model 6: Location of Start and Finish}

Logit (Location of start and finish) $=-0.894-0.368$ Motives to visit (1) -0.976 Motives to visit (2) -1.446 Motives to visit (3) +0.337 Motives to visit (4) +0.610 Motives to visit (5) -0.151 Motives to visit (6) + 0.641 Gender (1) - 0.001 Age - 19.493 Education (1) - 0.354 Education (2) - 0.186 Education (3) - 0.080 Education (4)

Interpreting statistically significant predictors, the analysed model reveals, that hikers coming for sport are 1.67 times more likely to choose a hiking trail according to location of start and finish and those coming for being in nature and 1.66 times more likely than those coming for other than specified reasons. Hikers with elementary education are less likely to choose hiking trail than those with university education $(\exp (\beta)=0.253)$.

\subsubsection{Model 7: Good Accessibility}

Logit $($ Good accessibility $)=-1.449+0.153$ Motives to visit $(1)-0.434$ Motives to visit $(2)-1.309$ Motives to visit (3) - 18.940 Motives to visit (4) - 19.352 Motives to visit (5) - 0.491 Motives to 
visit $(6)+0.437$ Gender (1) -0.020 Age -0.104 Education $(1)+0.260$ Education $(2)+0.193$ Education (3) +0.453 Education (4)

Studied model reveals that men are 1.89 times more likely to choose a hiking trail according to its accessibility than women. Hikers coming for seeing natural and cultural attractions are less likely to choose the hiking trail according to its accessibility than those coming for sports $(\exp (\beta)=0.377)$. The age is also statistically significant parameter in analysed model. The increase in age means the decrease in odds of choosing the hiking trail according to its accessibility $(\exp (\beta)=0.968)$

Table 2. Logit Models - Values

\begin{tabular}{|c|c|c|c|c|c|c|c|}
\hline & $\begin{array}{c}\text { Model 1: } \\
\text { Length of trail }\end{array}$ & $\begin{array}{c}\text { Model 2: } \\
\text { Appearance } \\
\text { of } \\
\text { surrounding }\end{array}$ & $\begin{array}{c}\text { Model 3: } \\
\text { Architecture } \\
\text { and } \\
\text { settlement }\end{array}$ & $\begin{array}{c}\text { Model 4: } \\
\text { Forest } \\
\text { surrounding }\end{array}$ & $\begin{array}{c}\text { Model 5: } \\
\text { Concrete } \\
\text { objects }\end{array}$ & $\begin{array}{c}\text { Model 6: } \\
\text { Location } \\
\text { of start } \\
\text { and finish }\end{array}$ & $\begin{array}{c}\text { Model 7: } \\
\text { Good } \\
\text { accessibility }\end{array}$ \\
\hline $\begin{array}{c}\text { Chi-square } \\
\text { (sig.) }\end{array}$ & 0.003 & 0.000 & 0.003 & 0.006 & 0.005 & 0.000 & 19.556 \\
\hline $\begin{array}{c}2 \text { Log } \\
\text { Likehood }\end{array}$ & 326.656 & 558.076 & 219.413 & 506.101 & 65.183 & 553.075 & 269.353 \\
\hline $\begin{array}{c}\text { Cox\&Snell } \\
\text { Square }\end{array}$ & 0.033 & 0.075 & 0.043 & 0.092 & 0.033 & 0.102 & 0.044 \\
\hline $\begin{array}{c}\text { Nagelkerke } \\
\text { R Square }\end{array}$ & 0.060 & 0.100 & 0.101 & 0.128 & 0.196 & 0.136 & 0.091 \\
\hline $\begin{array}{c}\text { Hosmer and } \\
\text { Lemeshow } \\
\text { Test (sig.) }\end{array}$ & 0.865 & 0.335 & 0.756 & 0.366 & 0.820 & 0.768 & 0.589 \\
\hline $\begin{array}{c}\text { Percentage } \\
\text { of right } \\
\text { prediction }\end{array}$ & 86.6 & 62.4 & 92.1 & 67.9 & 98.2 & 62.8 & 89.6 \\
\hline
\end{tabular}

\section{Conclusion}

Looking in detail on hiker's profile, we can conclude that typical hiker is a man with high school or university degree, 35 years old. The hiker's age correspondents to the results Lynn and Brown's research, but it is lower that Torbini's research results $[13,14]$. The education characteristic fits studied researches. The hypothesis that, there is no difference in personal characteristics between hikers coming for sportive motives and those coming for other motives, cannot be rejected.

Hikers choose a trail mainly (over 50\%) according to the surrounding landscape appearance. Hikers coming for sportive motives rank the motives as follows (from highly prefers to less preferred): landscape appearance, forest surrounding, concrete objects on the trail, accessibility, length of trail, location of start/finish, and settlement and architecture along the trail. Hikers coming for other than sportive motives have different preferred motives ranking them (from highly prefers to less preferred): landscape appearance, concrete objects on the trail, forest surrounding, length of trail, accessibility, location of start/finish, and settlement and architecture along the trail.

Although analysed models are statistically significant, not all parameters in estimated logit models are statistically significant. We can conclude that hikers coming to PLAs for sportive reasons are more likely to choose a hiking trail according to the length of the trail and the position of start/finish than hikers coming for nature. Hikers coming for sport motives are also more likely to 
choose a trail according to its length, its surrounding landscape appearance, existence of forest and accessibility than those coming to see cultural/natural attraction. However hikers coming for seeing natural/cultural attractions are more likely to choose a hiking trail according to the concrete objects on the trail than those coming for sportive motives.

Hikers coming for sportive motives are less likely to choose a trail according to proximity of architecture and concrete objects along the trail than hikers coming for visiting friends and relatives and hikers stopping on their further journey. There exists a higher odd that hikers coming for sportive motives choose a trail according to landscape appearance and forest surrounding than hikers coming for visiting friends and relatives; and according to length of trail and landscape appearance than hikers coming for business purposes.

\section{Acknowledgement}

The findings introduced in this paper arise from research made possible by a grant provided by the Faculty of Economics and Management, Czech University of Life Sciences in Prague no. 20131042.

\section{References}

1. J. R. Walker, C. S. Shafter, Mode of Experience on a Recreational trail: An Examination of How Hikers and Mountain Bikers Focus Their Attention. Journal of Park and Recreation Administration. 29, 2, 21-8. (2011)

2. R. J. Virdin, R. Schreyer, Recreation Specialization as an Indicator of Environmental Preferences. Environment and Behaviour. 20, 6, 721-739. (1988)

3. P. Chhetri, C. Arrowsmith, Jackson, M. Determining hiking experiences in nature-based tourist destinations. Tourism Management. 25, 31-34. (2004) N. A Lynn, R. D. Brown, Effects of recreational use impacts on hiking experiences in natural areas. Landscape and Urban Planning. 64, 77-87. (2003)

4. E. I. F. Torbidoni, Managing for Recreational Experience Opportunities: The Case of Hikers in Protected Areas in Catalonia, Spain. Environmental Management. 47, 482-496. (2011)

5. Lynn, N. A., \& Brown, R. D. Effects of recreational use impacts on hiking experiences in natural areas. Landscape and Urban Planning. 64, 77-87. (2003)

6. S. Wall-Reinius, L. Back, Changes in Visitor Demand: Inter-year Comparison of Swedish Hikers' Characteristics, pref. and Exper. Scandinavian J. of Hospitality and Tourism, 11, 38-53. (2012)

7. J. Nykodym, J. Mitas, Prurezova studie pohybove activity dospele populace Jihomoravskeho region. Telesna kultura. 34, 1, 49-64. [in Czech] (2011)

8. N. J. D. Nagelkerke, A note on a general definition of the coefficient of determination. Biometrika, 78, 691-692 (1991)

9. M. A. Pardo A., Ruiz, SPSS 11-Guide for Data Analysis. Mc Graw-Hill, Madrid [Spanish] (2002) 